\title{
An Empirical Study on the Generation Mechanism of NIMBY Conflicts of Construction Projects
}

\begin{abstract}
In the highly overlapped contexts of urbanization and social transformation, and with the advent of the "Risk Society," the social issues, called "Not in My Back Yard (NIMBY)" conflicts, caused by the construction or operation of the NIMBY projects have become a serious problem in China. Hence, it is in urgent need to find out the influencing factors and discover the generation mechanism of the NIMBY conflicts. From the perspective of social conflict theory, the authors built a process model of the NIMBY conflicts on the basis of identifying stakeholders and analyzing their interest interaction. Thereafter, the authors conducted a questionnaire survey, followed by exploratory factor analysis (EFA) revealing the underlying influencing factors of the NIMBY conflicts. Finally, they performed the confirmatory analysis method of Structural Equation Modeling to test the preliminary research hypothesis of the model and its interaction path in AMOS 18.0, with the results showing that unequal exchange and consensus mobilization will contribute to the formation of common consciousness of the opposition party, the opposition party's common consciousness and action mobilization affects the generation of social conflicts. The process model reveals the generation mechanism of the NIMBY conflicts, and it facilitates further investigations in the governance of the NIMBY conflicts.
\end{abstract}

Keywords: NIMBY conflicts, social conflict, construction projects, mechanism, empirical study

Manuscript received September 2, 2015; accepted December 10, 2015

Guang-she Jia, Song-yu Yan ( $\bowtie)$, Wen-jun Wang

School of Economics \& Management, Tongji University, Shanghai 200092, China

Email: yan_songyu@163.com

Ralf Müller

Department of Leadership \& Organizational Behavior, Norwegian Business School, Oslo, Norway

Chen Lin

Shanghai Airport Group Co., Ltd., Shanghai 201207, China

\section{Introduction}

In the past 30 years, especially since the 1990 s, the urbanization of China has speed up evidently, with a rapid growth and an urbanization rate between $28.5 \%$ in 1994 to $54.7 \%$ in 2014 . The Government declared that in the next 10 years China will continue to push forward the urbanization process (China Government, 2013). It is clear that the expansion of the cities and the realization of urban functions cannot be separated from the construction of comprehensive supporting facilities, which will lead to an increase in construction projects. In addition, with the government reform and open-up policy proceeding, the economic structure is in a continuous readjustment, the whole social structure is in a further polarization and social contradictions enter a peak period. In the highly overlapped contexts of urbanization and social transformation, construction and operations projects, such as coal-fired power plant, nuclear power plant, destructor plant and airports are public projects that often will have a strong negative effect on neighborhood residents. This usually results in fierce resistance and the "Not in My Back Yard" (NIMBY) effect (Kraft \& Clary, 1991).

In recent years, the social conflicts caused by the NIMBY projects continued to rise year over year. This not only had a negative effect on the construction of foundation facilities, but also may harm the stability of the society. Therefore, this paper tries to figure out the following two research questions.

RQ1: What factor(s) will lead to the NIMBY conflicts?

RQ2: What is the interaction of the influencing factor(s), and what is the generation mechanism of the NIMBY conflicts?

It is in urgent need to find out a feasible methodology to identify the factors and their interaction, so as to offer valuable information for governance. Based on the social conflict theory, this paper established a process model to analyze the inner generation mechanism of the NIMBY conflicts.

This paper continues with a literature review, from which a process model is derived. This is followed by sections for empirical testing and discussion of the results. The paper 
finishes with a conclusion section that answers the research questions.

\section{Literature review}

\subsection{The "Not in My Back Yard" theory}

Since 1977, the time O'hare (1977) $>$ first proposed the concept "Not in My Back Yard" (NIMBY) in the article "Not On My Block You Don't': Facilities Sitting and the Strategic Importance of Compensation," the relevant concept of the NIMBY projects and the NIMBY conflicts have drawn extensive attention of the academia and the media. "NIMBY project" is a kind of facilities which can be beneficial for the public but may inevitably exert negative externalities on public health and property value in the affected localities, which will lead to the so-called "Not in My Back Yard" impulse (Devine-Wright, 2005; Tan \& Hu, 2013). Correspondingly, the "NIMBY conflicts" is a kind of resistance behavior done by the affected residents in order to resist the construction and operation of the NIMBY facilities.

Researchers have reached a basic consensus on the factors that cause the conflicts. In summary, regarding the uneven distribution of "cost - benefit" as the core factor, the influence factors gradually derived to non-economic aspects, such as the inaccessibility of participating in the decision-making mechanism, the lack of public participation mechanism and the mistrust of the government, enterprises even experts. This characteristic of inequality distribution is the direct cause of conflicts because the surrounding residents have to bear the economic and environmental costs while others gain benefit without any cost (Bosley, P. \& Bosley, K., 1988; Wolsink, 1994). Khun and Ballard (1998) surveyed the Canada site selection of a sewage treatment project and found that the lack of decision making and public participation mechanism is one of the important factors affecting the NIMBY conflicts Research showed that the distrust in experts and technology, the suspicion of standards in enterprise operation and ability of government's public management were easy to trigger collective action (Anderson, 2013; Hunter \& Leyden, 1995; Matheny \& Williams, 1985).

Although researchers have made considerable achievements, most of the outcomes were concentrated on the scope definition, the interest analysis of stakeholders, and the identification of the influence factors of NIMBY projects. All of these embodied a static research method. Actually, the interaction of its influence factors is in a dynamic process rather than stay static state. So, a dynamic research perspective is needed to reveal the interactive relationship between various factors and their evolution path. In addition, the most frequent used theory in these research projects is the economics of utility theory, but the theory is too weak to explain the evolution path in such a dynamic environment, thus, it is essential to find a suitable theory and method for this research. The authors identified the Social Conflict Theory as being an appropriate theoretical perspective, because it provides the required dynamics and interactions. Accordingly, this paper analyzes the influence factors of the NIMBY conflicts and their interactions from the perspective of the Social Conflict Theory.

\subsection{The social conflict theory}

As the core issue of social conflict, the research of conflict generation mechanism is always the focus. From structuralism represented by Marx and psychologism represented by Le Bon (1897) to exchange theory represented by Blau (1964), then to resource mobilization theory represented by McCarthy and Zald (1977), each school tried to illustrates the generation mechanism from one aspect but none survived from the dilemma that solve one problem only to find another cropping up. While applying these theories to explain the social conflicts, something will always be found that cannot be explained. In consequence, on the basis of critical absorption of classical theory, a more scientific theory called constructivism theory was established. Constructivism held that social structure, common consciousness and individual rationality were important variables resulting in social conflicts, and the mobilization behavior was the key transformation process in the generation of social conflicts (Li, 2009). From the perspective of constructivism, the actors of conflict had three characteristics. First, they are social beings, they are one part of social structure and social environment rather than isolated in society. Second, they are rational and good at calculating costs and benefits. Third, they are emotional at the same time and will be influenced by emotional factors such as resentment and sense of deprivation (Zeng \& Luo, 2006). Therefore, under a particular social structure, actors constantly perceive all kinds of information from the external environment, calculate rationally and evaluate emotionally, so as to construct and update their cognition. On this basis they choose the appropriate strategies in the generation of social conflicts.

Dahrendorf (1959) divided the generation process into four stages: authority relationship, potential conflict, explicit conflict, and conflict. Pondy (1967) emphasized the importance of conflict perception and adjusted the process to the following five stages: potential conflict, perceived conflict, felt conflict, explicit conflict, and conflict, with "authority relationship" incorporated into "potential conflict." Korsgaard, Jeong, Mahony, and Pitariu (2008) thought the boundaries of perceived conflict and felt conflict in Pondy's model was fuzzy. Therefore, these two stages were combined and collectively referred to as "conflict perception" so as to describe the process more concise and clear.

On the basis of absorbing western social conflicts theory and combining special social conditions of China, domestic 
study achievements of social conflict provided useful literatures for this research. Zhao (2005) combed the western social conflicts theory and summarized the generation mechanism as "hange, structure and discourse." Liu (2004) thought the possibility of social conflicts was a function and based on which established a model where the variables were "the production and interpretation of resentment," "activists and their ability of organization" and "rational choice of potential participants." This model could explain the generation of macro social movements and elaborate the reason why individual actors participate in collective action, but it failed to reveal the mobilization mechanism and the change of actors.

\section{The generation mechanism of NIMBY conflicts}

\subsection{Stakeholder analysis}

Stakeholder refers to a group, organization, member, or system that affects or can be affected by an organization's actions (Freeman, 2010). According to this definition, the stakeholders of NIMBY projects can be considered including government, developers, contractors, consultants, affected groups, service groups, the media and nonprofit organizations, etc. Because of the differences of value orientation and interest demand, the stakeholders can be divided into two basic opposing parties (opponents and proponents) and a neutral party.

In this particular field of NIMBY projects, whether government-invested projects or enterprise-invested projects, they can greatly promote the development of regional economy and improve the governance performance with their operation. Thus, government and developers often join together into a community. Contractors and consultants are employed by developers, to a large extent they depend on the developers' will and altogether set up the construction party (proponents). On the other hand, the affected groups refer to those nearby people who suffer most from the projects. As the main participants in the NIMBY conflicts, they constitute the opposition party (opponents). As for the service group, the media and nonprofit organizations, due to the little effects on their interests, combined with their own limitations, they are usually in a neutral role in the interaction. As a result, the government, developers and affected groups constitute the main stakeholders. This paper doesn't aim to analyze all the stakeholders, but will take the construction party and opposition party as the research object, mainly analyzing the interactions between the government, developers and affected groups in the generation of the NIMBY conflicts.

\subsection{The driving mechanism of the NIMBY conflicts}

Based on the above analysis of the generation processes, the concept of conflict was divided into four stages in this paper: potential conflict, conflict perception, explicit conflict, and conflict results. When conflict behavior took place, it always had its own development path and evolution rules rather than an accidental event. He (2009) concluded that the NIMBY conflicts were the result of both mobilizing capacity and anti-mobilizing capacity. Under the driving mechanism of the NIMBY conflicts, opponents and proponents kept on taking measures to struggle for their interests (Figure 1). There are two kinds of capacities; one is the mobilizing capacity driving by the opponents, aiming at promoting conflicts, and the other is the antimobilizing capacity driving by the proponents, trying to prevent acting.

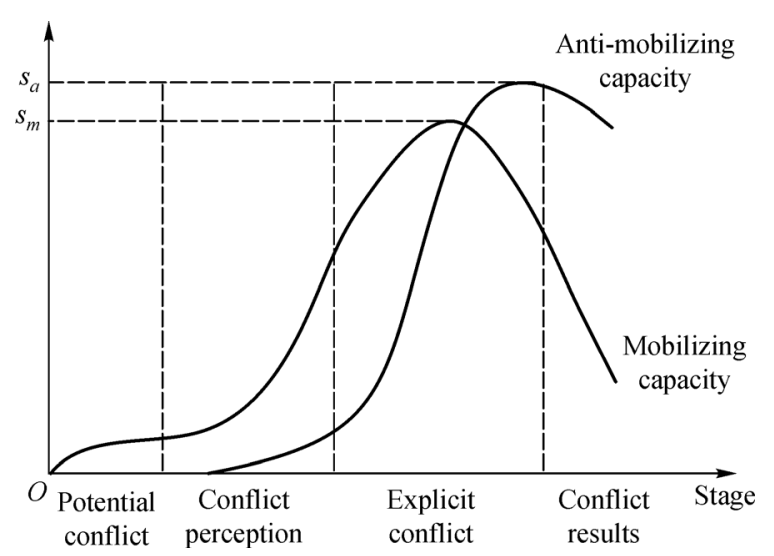

Figure 1. The driving mechanism of NIMBYconflicts. Adapted from the paper "The NIMBY conflicts in China: based on the analysis of events" by $\mathrm{He}(2009)$.

In the potential conflict stage, most of opponents are in a status of "ignorance," but a few grassroots activists highly concerning the NIMBY problem have awaken and begun to take individual petition or complaint action. On the other hand, the construction party ignores grassroots activists' protests, staying the same or blocking information. At this moment, the contradictions arise and conflict is sprouting.

The conflict perception stage is the most important phase to mobilize the affected groups. Under the mobilization of grassroots activists, small-scale groups are formed and common consciousness unceasingly strengthened with the "worry" and "dissatisfaction" gradually accumulated. The anti-mobilization mechanism is activated with the process of mobilization capacity. Proponents respond to opponents' demand, begin to intervene with the media and try to emphasize the positive effect of the projects through professional statement.

In explicit conflict stage, small-scale resistance has evolved into an open confrontation between opponents and proponents. As the conflict evolves, large-scale and wellorganized conflict burst. Considering the social stability and under the pressure of the public, the determination of 
supporting the project made by the government is changed and they are forced to reevaluate the project.

Finally, the conflicts generally end in the compromise of the construction party (with few exceptions), and all or part of the opponents' demands are met. Conflict behavior subsides, social order gradually returns to normal, and the media carries out the subsequent work.

Overall, opponents initiate the mobilization capacity, while the anti-mobilizing capacity emerges more as a passive response, subsequent to the mobilizing capacity. In potential conflict and conflict perception phases, it is most likely the best time to control the situation, because the mobilizing capacity is in its start-up. However, as long the mobilizing action has not reached the government's attention and triggered related action; it is difficult to attract enough attention, which tends to lead to missing the optimal timing of interventions.

\subsection{The process model of NIMBY conflicts}

Based on the social conflict theory and review of conflict events in China (He, 2009; Sun, 2013; Zheng, 2011), the general generation pattern of NIMBY conflicts can be derived from that. The established process model is shown in Figure 2.

(1) In the potential conflict stage, because of the inherent attribute of NIMBY projects that costs and benefits are separated, the affected group's interests will surely be influenced, along with the dominant proponents in the social structure pushing the construction of the projects through resources and power. This will inevitably cause a fact of "unequal exchange."

(2) In the conflict perception stage, a process of "common consciousness construction" is fermented, mainly including two critical transitional steps. The first step is from "unequal exchange" to "common consciousness," which is proceeded by the grassroots activists' mobilization and most of the affected residents can be conscious of its negative aspects, then forming the common consciousness of unfairness and dissatisfaction. The second step is through the process of resource mobilization, finishing the change from "common consciousness" to "conflict behavior." The former step is called "consensus mobilization" process, namely through public discourse level, persuasive communication level and consensus promotion level (Morris, 1992), producing a group of potential participants with a common consciousness, which means the grassroots activists win the support of discourse and ideology and the necessary conditions of conflict is possessed. The latter step corresponds to the process of "ction mobilization," through analyzing the possibility of successful conflict, the cost of participating and the benefit of conflict results, along with the stimulation of their social network, trying to activate the potential participants, making them become actors. At this moment, the sufficient condition of conflict is reached. The differentiation path of affected residents in the process of "common consciousness construction" is shown in Figure 3. On the other hand, the construction party is trying to prevent the conflict through various approaches of "anti-consensus mobilization" and "anti-action mobilization."

(3) When it comes to the stage of explicit conflict, the

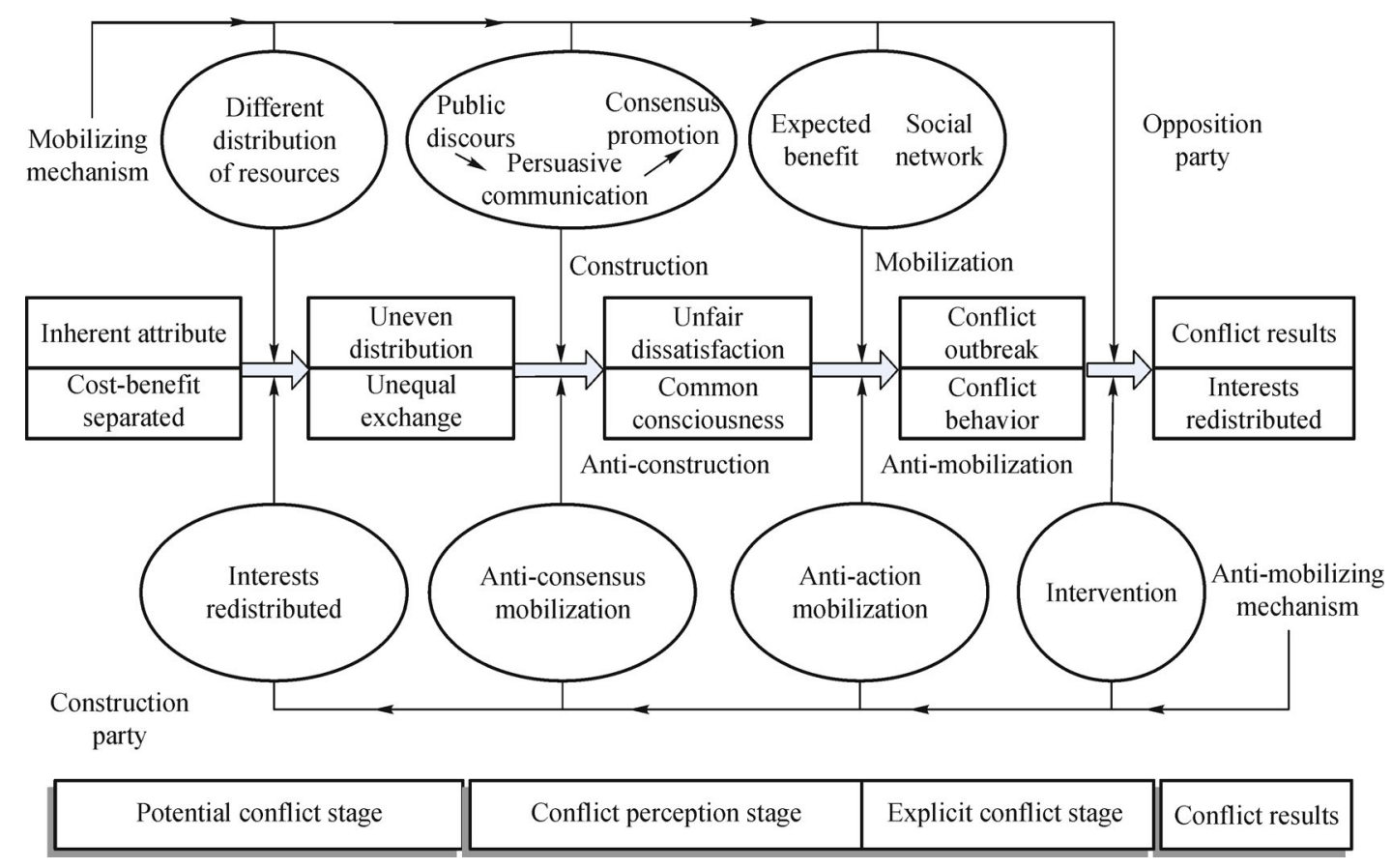

Figure 2. The process model of NIMBY conflicts. 


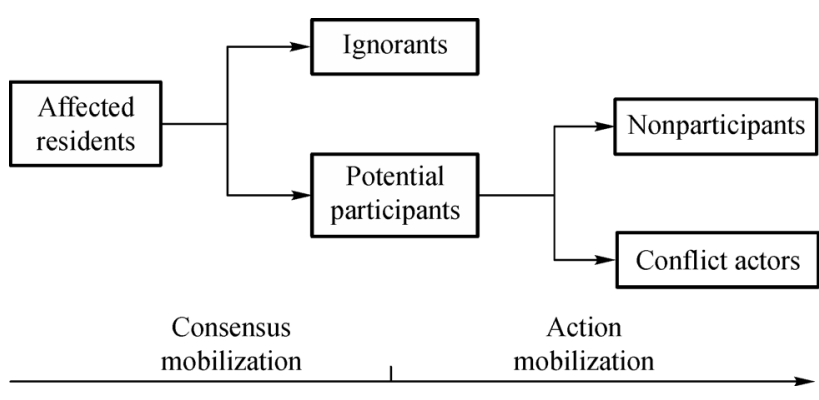

Figure 3. The differentiation path of affected residents in the process of "common consciousness construction."

NIMBY conflict breaks out entirety, the anti-mobilizing mechanism of the construction party is in full swing and competing directly and fiercely with opponents around the different interests.

(4) In the conflict results stage, with the senior government intervening, the interest is redistributed to satisfy the demands of opponents and the conflict is finally subsided.

\section{Research design}

The purpose of the research is to explore the generation factors of NIMBY conflict and their interrelation. Hence, the research is focused on analyzing the two phases of "potential conflict" and "conflict perception," rather than the other aspects, for example, conflicts intervention, disposition, etc.

\subsection{Research hypothesis}

\subsubsection{Hypothesis}

To improve the operability of empirical study, the research simplifies the process model of NIMBY conflicts while keeping the core factors. The four core hypotheses are extracted from the above model, and a simplified model is built as shown in Figure 4:

H1: The unequal exchange affects the formation of common consciousness of the opposition party;

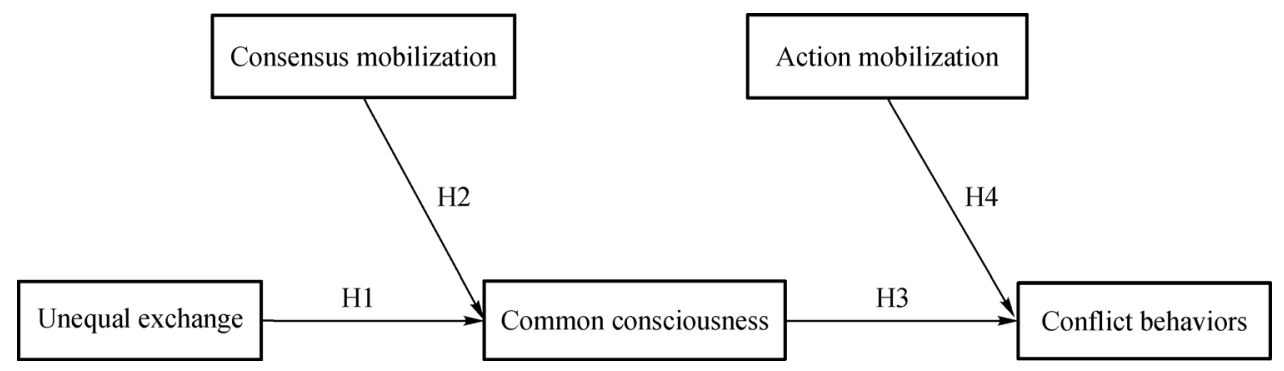

$\mathrm{H} 2$ : The consensus mobilization affects the formation of common consciousness of the opposition party;

H3: The common consciousness of the opposition party affects the generation of conflicts;

H4: The action mobilization affects the conflict behaviors.

\subsubsection{Questionnaire design and sample selection}

(1) Questionnaire design. Based on the literature review and the simplified model, five core factors including "unequal exchange," "consensus mobilization," "common consciousness," "action mobilization" and "conflict behaviors" are selected and divided into two classes: "the state variables" and "the process variables." According to Sun (2005) and Liu's (2004), a questionnaire including 17 questions was designed to describe those variables as shown in Table 1, and Likert scale was used to mark, from 1 to 5 to represent "totally disagree," basically disagree," "uncertain," "basically agree" and "totally agree." The interviewees were acquired to answer those questions according to the facts.

(2) Sample selection. This test gave out 174 questionnaires altogether, and $76.2 \%$ (132) of them was retrieved, respondents came from various social roles, government staff, engineers, ordinary citizens, students, media and nonprofit organizations. The feedback showed a high level of educational background and most of the respondents had known or even participant in the NIMBY conflicts. Descriptive statistics about the respondents are summarized in Table 2.

\subsection{Empirical research}

\subsubsection{Factor analysis}

The purpose of factor analysis is to extract factor structure from a multitude of indicators, including reliability analysis, Eligibility analysis and factor extraction. The search results show that there is no plenty of literature and mature questionnaire of the generation mechanism of NIMBY conflicts. Hence, this paper chooses the exploratory factor analysis (EFA) to do the research as EFA can be performed to explore the underlying factors when lacking 
Table 1

The Structure of the Scale

\begin{tabular}{|c|c|c|c|}
\hline Variable types & Key variables & Index code & Index names \\
\hline \multirow{11}{*}{ State variables } & \multirow{6}{*}{$\begin{array}{l}\text { Unequal exchange } \\
\mathrm{U}\end{array}$} & U1 & Negative effects of NIMBY \\
\hline & & $\mathrm{U} 2$ & Positive effects of NIMBY \\
\hline & & $\mathrm{U} 3$ & Interests Compensation \\
\hline & & $\mathrm{U} 4$ & Degree of public participation \\
\hline & & U5 & Legitimacy of decision process \\
\hline & & U6 & Definition of public interest \\
\hline & \multirow{3}{*}{$\begin{array}{c}\text { Common consciousness } \\
\text { C }\end{array}$} & $\mathrm{C} 1$ & Anger \\
\hline & & $\mathrm{C} 2$ & Collective identity \\
\hline & & $\mathrm{C} 3$ & Internal solidarity \\
\hline & \multirow{2}{*}{$\begin{array}{l}\text { Conflict behaviors } \\
\text { B }\end{array}$} & B1 & Participation in conflict actions \\
\hline & & B2 & Organization conflict actions \\
\hline \multirow{6}{*}{ Process variables } & \multirow{3}{*}{$\begin{array}{c}\text { Consensus mobilization } \\
\text { M }\end{array}$} & M1 & Public discourse \\
\hline & & M2 & Persuasive communication \\
\hline & & M3 & Consensus promotion \\
\hline & \multirow{3}{*}{$\begin{array}{c}\text { Action mobilization } \\
\text { A }\end{array}$} & A1 & Political opportunity structure \\
\hline & & $\mathrm{A} 2$ & Expected benefit of action \\
\hline & & $\mathrm{A} 3$ & Social networks \\
\hline
\end{tabular}

Table 2

Descriptive Statistics about the Respondents

Number of respondents

Percentage $(\%)$

Social roles

Government staff

17

12.88

Engineers

27.27

Ordinary citizens

34.85

Students

18.94

Media and Non-profit organizations

6.06

Educational background

Doctor

Master

12.12

Undergraduate

25.76

Junior college

35.61

Below junior college

23.48

Cognition of NIMBY conflicts

Personal involvement

Family involvement

Friends involvement

12.88

Never involvement but heard

55.30

Never heard

25.00 
robust theoretical foundation (Fernandes, Ward, \& Araújo, 2014).

(1) Reliability analysis. Nunnally, Bernstein, and Berge (1967) Cronbach's Alpha threshold of 0.5 was used. Table 3 shows the Cronbach 's Alpha coefficient for each constrict as greater than 0.5 , which indicates that there are good consistency between these items, namely, this questionnaire has an acceptable reliability.

(2) Eligibility analysis. Kaiser-Meyer Olkin test (KMO) $>0.500$, and Bartlett's test of less than 0.05, are indicators for eligibility of the data for factor analysis (Hair, Black, Babin, Anderson, \& Tatham, 2006). Table 4 show that these thresholds are met with an overall $\mathrm{KMO}$ of 0.842 , and a Bartlett's test of 0.000 .

(3) Factor extraction. Principal component analysis with Varimax rotation was used to extract factors. The rotated component matrix is shown in Table 5. Table 6 shows that the extracted three factors can explain the $69 \%$ of the total variance, meet the minimum requirement of $50 \%$ (Hair, Black, Babin, Anderson, \& Tatham, 2006).

From the rotated component matrix of state variables, it can be seen that the extracted three factors are identical with the theoretical structure of the scale. A similar conclusion can be found in the rotated component matrix of process variables (Table 7).

\subsubsection{Path analysis}

(1) Path analysis model

Confirmatory Factor Analysis was done using Structural Equation Modeling (SEM). This combines factor analysis and regression analysis, to test the relationship between the observed variables, latent variables and error variables $(\mathrm{Wu}, 2010)$. Based on the outcome of the factor analysis,

Table 3

Reliability Statistics

\begin{tabular}{lcccc}
\hline Factor codes & Factors & Index & Cronbach' $\alpha$ \\
\hline $\mathrm{U}$ & Unequal exchange & U1、U2、U3、U4、U5、U6 & 0.860 \\
$\mathrm{M}$ & Consensus mobilization & M1、M2、M3 & 0.716 \\
$\mathrm{C}$ & Common consciousness & C1、C2、C3 & 0.762 & 3 \\
$\mathrm{~A}$ & Action mobilization & A1,A 2、A 3 & 0.667 & 3 \\
$\mathrm{~B}$ & Conflict behavior & B1、B2 & 0.717 \\
\hline
\end{tabular}

Table 4

Eligibility Statistics

\begin{tabular}{lccc}
\hline \multirow{2}{*}{ Kaiser-Meyer-Olkin } & \multicolumn{3}{c}{ Bartlett's test } \\
\cline { 2 - 4 } & Approximate $\chi^{2}$ distribution & Df & Sig. \\
\hline 0.842 & 988.470 & 136 & 0.000 \\
\hline
\end{tabular}

Table 5

The Rotated Component Matrix of State Variables

\begin{tabular}{|c|c|c|c|c|}
\hline \multirow{2}{*}{ Factor } & \multirow{2}{*}{ Index } & \multicolumn{3}{|c|}{ Component } \\
\hline & & 1 & 2 & 3 \\
\hline \multirow{6}{*}{ Unequal exchange(U) } & Negative effects of NIMBY (U1) & 0.652 & 0.317 & 0.218 \\
\hline & Positive effects of NIMBY (U2) & 0.700 & 0.287 & 0.257 \\
\hline & Interests compensation (U3) & 0.662 & 0.552 & 0.127 \\
\hline & Degree of public participation (U4) & 0.749 & 0.276 & -0.030 \\
\hline & Legitimacy of decision process (U5) & 0.755 & 0.191 & 0.158 \\
\hline & Definition of public interest (U6) & 0.768 & -0.092 & 0.075 \\
\hline \multirow{3}{*}{$\begin{array}{l}\text { Common consciousness } \\
\text { (C) }\end{array}$} & Anger (C1) & 0.411 & 0.575 & 0.484 \\
\hline & Collective identity (C2) & 0.318 & 0.712 & 0.302 \\
\hline & Internal solidarity (C3) & 0.082 & 0.865 & -0.045 \\
\hline \multirow{2}{*}{ Conflict behavior(B) } & Participation in conflict actions (B1) & 0.030 & 0.164 & 0.867 \\
\hline & Organization conflict actions (B2) & 0.205 & 0.009 & 0.836 \\
\hline
\end{tabular}


the initial PA-LV model (path analysis with latent variables) was established in AMOS 18.0. According to the opinion of Chi and Adams (2002), the most effective way to improve model goodness of fit is stepwise refinement method. After testing the parameters and the overall goodness of fit, the model was adjusted and optimized shown in Figure 5. The unequal exchange and consensus mobilization influenced the formation of

Table 6

The Extent of Variance Explanation of State Variables

\begin{tabular}{lccccccc}
\hline \multirow{2}{*}{ Component } & \multicolumn{3}{c}{ Initial eigenvalue } & & \multicolumn{3}{c}{ The rotated eigenvalue } \\
\cline { 2 - 4 } & Sum & \% of variance & Accumulation \% & & Sum & \% of variance & Accumulation \% \\
\hline 1 & 5.074 & 46.129 & 46.129 & & 3.393 & 30.843 & 30.843 \\
3 & 1.390 & 12.640 & 58.769 & & 2.222 & 20.196 & 51.038 \\
\hline
\end{tabular}

Table 7

The Rotated Component Matrix of Process Variables

\begin{tabular}{|c|c|c|c|}
\hline \multirow{2}{*}{ Factor } & \multirow{2}{*}{ Index } & \multicolumn{2}{|c|}{ Component } \\
\hline & & 1 & 2 \\
\hline \multirow{3}{*}{$\begin{array}{l}\text { Consensus mobilization } \\
\text { (M) }\end{array}$} & Public discourse (M1) & 0.810 & 0.223 \\
\hline & Persuasive communication (M2) & 0.794 & 0.077 \\
\hline & Consensus promotion (M3) & 0.763 & 0.019 \\
\hline \multirow{3}{*}{$\begin{array}{l}\text { Action mobilization } \\
\text { (A) }\end{array}$} & Political opportunity structure (A1) & 0.174 & 0.710 \\
\hline & Expected benefit of action (A2) & -0.051 & 0.810 \\
\hline & Social networks (A3) & 0.173 & 0.789 \\
\hline
\end{tabular}

Note: The extracted two factors can explain the $62.840 \%$ of the total variance.

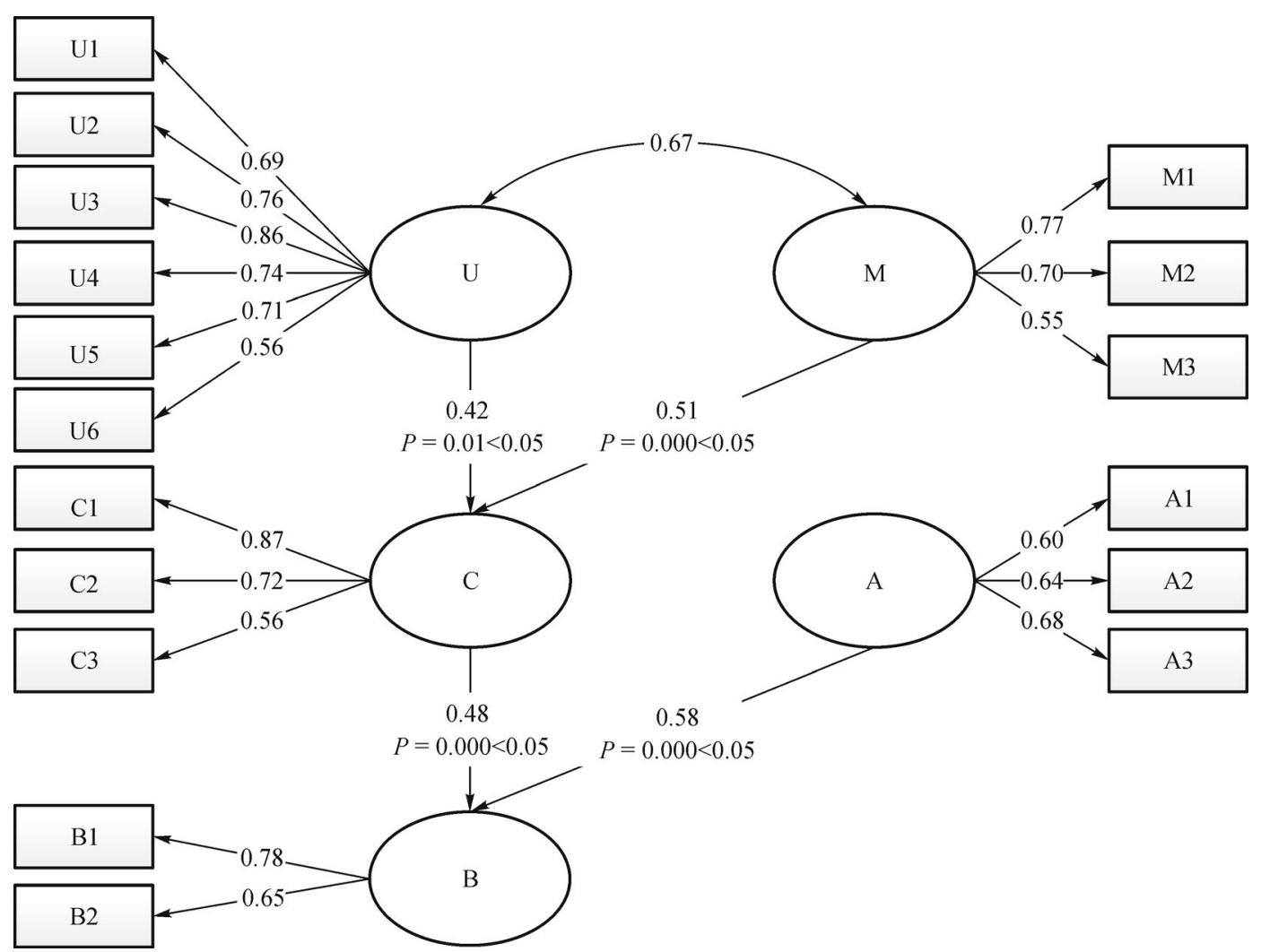

Figure 5. Path analysis model of the generation of NIMBY conflicts. 
Table 8

The Match Degree of Model

\begin{tabular}{|c|c|c|c|}
\hline Statistic & Standard & Modified model & Judgment \\
\hline \multicolumn{4}{|c|}{ Absolute index } \\
\hline$\chi^{2}$ & $P>0.05$ (miss) & $112.364(P=0.207>0.05)$ & Pass \\
\hline RMSEA & $<0.08$ (if $<0.05$, good) & 0.029 & Good \\
\hline GFI & $>0.90$ & 0.915 & Pass \\
\hline \multicolumn{4}{|c|}{ Incremental index } \\
\hline CFI & $>0.90$ & 0.987 & Pass \\
\hline IFI & $>0.90$ & 0.988 & Pass \\
\hline TLI & $>0.90$ & 0.983 & Pass \\
\hline \multicolumn{4}{|c|}{ Contracted index } \\
\hline PNFI & $>0.50$ & 0.662 & Pass \\
\hline PCFI & $>0.50$ & 0.733 & Pass \\
\hline$\chi^{2} / \mathrm{df}$ & $<2.00$ & 1.113 & Pass \\
\hline AIC & Theoretical $<$ Independent $\&<$ Saturation & $\begin{array}{c}216.364<232.931 \\
216.364<1074.076\end{array}$ & Pass \\
\hline CAIC & Theoretical $<$ Independent $\&<$ Saturation & $\begin{array}{c}418.270<900.069 \\
418.270<1140.084\end{array}$ & Pass \\
\hline
\end{tabular}

common consciousness and the path coefficient were 0.42 and 0.51 .The common consciousness and action mobilization influenced the generation of social conflicts behavior and the path coefficient were 0.48 and 0.58 .

(2) Model testing

Model testing mainly includes two aspects of tests, one is parameter test and the other is goodness of fit test. In PALV model, path coefficient refers to the regression coefficient of latent variables, and loading coefficient refers to the regression coefficient between latent variables and index variable. The main purpose of parameter test is testing the significance of path coefficient and loading coefficient. The results of parameter test is shown in Figure 5, the significant probability $\mathrm{p}$ is lower than 0.05 , which indicates that all the coefficients have a very high significance.

After passing parameter test, the overall test of goodness of fit is needed in order to evaluate the match degree of theoretical model and measured data. The testing results show that $\chi^{2}$ is 112.364 and significant probability $P$ is $0.207>0.05$, thus theoretical model and actual data can fit well (Table 8), therefore the matching of model and data are good.

\subsection{Additional finding}

As a result of the above analysis, all of the four core assumptions had been proved in empirical study, and the correctness of the process model of NIMBY conflicts was proved further. The model not only validated the key role "unequal exchange" played in the generation of NIMBY projects, but also proved that "consensus mobilization" and "action mobilization" had important transition effect on the process.

In addition, in the process of revising the path model, the authors found that the co-variant parameter between "unequal exchange" and "consensus mobilization" reached 0.67 , which also showed high significance. This fairly strong interactive relationship is unexpected. This maybe because the greater the degree of inequality, the demands and the emotion of the opposition party will be more intense and the construction party will tend to control the negative information and emphasize the positive effect, which will influence the way of consensus mobilization. On the other hand, the way chosen to establish the common consciousness will lead to the asymmetric information between the two parties and the degree of "unequal exchange" will be aggravated. To some extent, this additional finding reflected that the generation of social conflict not only relied in the mechanism of evolution but also because of the interaction of key variables.

\section{Conclusions and further study}

In the paper, the stakeholders of the NIMBY projects were mainly divided into two opposing parties, and then the characteristics and mobilizing mechanism of the two parties around different interests in the four stages of the lifecycle of NIMBY conflicts was discussed. Based on the theory of social constructivism, along with specific social background of China, a process model was established that shows the evolution path of conflicts from potential conflict, conflict perception, and explicit conflict to conflict results. Furthermore, the empirical study indicated the inherent characteristics of the NIMBY projects, social 
structure, common consciousness and mobilization process were the critical factors of causing conflicts. The PA-LV model run in AMOS 18.0 showed that the unequal exchange and consensus mobilization influenced the formation of common consciousness, the common consciousness and action mobilization influenced the generation of social conflicts behavior, and all of them have a high significance $(P<0.05)$.

In the paper, the authors combined the NIMBY conflicts with social structure, under the domain of engineering sociology, elaborated the transition way from unequal exchange to conflicts behavior. Taking a dynamic analysis method, the interaction relationship of factors can be demonstrated clearly, especially the consensus mobilization process and action mobilization process, which provide a new way of studying NIMBY conflicts. Though the authors took several aspects of sociology, such as the social structure, psychology, mobilization process, etc. into consideration when studied the generation mechanism, there is still a long way to go so as to get a comprehensive model because of the very complicated social environment.

The paper reveals the generation mechanism of NIMBY conflicts, it can provide some reference for the governance of the NIMBY conflicts in China. The process model and implied conflict theory can provide the construction party with a more reasonable and justified way of accessing the project and take appropriate measures to communicate with the affected group.

\section{References}

Anderson, C. (2013). The networked minority: how a small group prevailed in a local wind farm conflict.Energy Policy, 58, 97-108.

Blau, P. M. (1964). Exchange and power in social life. Piscataway, New Jersey: Transaction Publishers.

Bosley, P., \& Bosley, K. (1988). Public acceptability of California's wind energy developments: three studies. Wind Engineering, 12, 311-318.

Chi, C. C., \& Adams, E. I. (2002). National identity and NATID: an assessment in Yemen. International Marketing Review, 19, 637-662.

China Government. (2013). The communiqué of the third plenary session of 18 of the communist party of China. Retrieved from http://news. xinhuanet.com/house/suzhou/2013-11-12/c_118113773.htm.

Dahrendorf, R. (1959). Class and class conflict in industrial society. Redwood City, California: Stanford University Press.

Devine-Wright, P. (2005). Beyond NIMBYism: towards an integrated framework for understanding public perceptions of wind energy. Wind Energy (Chichester, England), 8, 125-139.

Fernandes, G., Ward, S., \& Araújo, M. (2014). Developing a framework for embedding useful project management improvement initiatives in organizations. Project Management Journal, 45, 81-108.

Freeman, R.E. (2010). Strategic management: a stakeholder approach. Cambridge: Cambridge University Press.

Hair, J.F., Black, W.C., Babin, B.J., Anderson, R.E., \& Tatham, R.L.
(2006). Multivariate data analysis (Vol. 6). Upper Saddle River, New Jersey: Pearson Prentice Hall.

He, Y. (2009). The NIMBY conflicts in China: based on the analysis of events. Open Times, 12, 102-114.

Hunter, S., \& Leyden, K. M. (1995). Beyond NIMBY: explaining opposition to hazardous waste facilities. Policy Studies Journal: the Journal of the Policy Studies Organization, 23, 601-619.

Korsgaard, M. A., Jeong, S. S., Mahony, D. M., \& Pitariu, A. H. (2008). A multilevel view of intragroup conflict. Journal of Management, 34 , 1222-1252.

Kraft, M. E., \& Clary, B. B. (1991). Citizen participation and the NIMBY syndrome: public response to radioactive waste disposal. Western Political Quarterly, 44(2):299-328.

Kuhn, R. G., \& Ballard, K. R. (1998). Canadian innovations in sitting hazardous waste management facilities. Environmental Management, 22, 533-545.

Le Bon, G. (1897). The crowd: A study of the popular mind. [No location]: Fischer.

Li, W. (2009). The practice of collective action: sociological analysis of farmers' collective petitions (Unpublished doctoral dissertation). Shandong University, Shandong.

Liu, N. (2004). Resentment, mobilization structure and the rational choice: the analysis of the possibility of a collective action in China's urban areas. Open Times, 4, 57-70.

Matheny, A. R., \& Williams, B. A. (1985). Knowledge vs. NIMBY: assessing Florida's strategy for sitting hazardous waste disposal facilities. Policy Studies Journal: the Journal of the Policy Studies Organization, 14, 70-80.

McCarthy, J. D., \& Zald, M. N. (1977). Resource mobilization and social movements: a partial theory. American Journal of Sociology, 82, 1212-1241.

Morris, A. D. (1992). Frontiers in social movement theory. New Haven, Connecticut: Yale University Press.

Nunnally, J. C., Bernstein, I. H., \& Berge, J. M. T. (1967). Psychometric theory (Vol. 226). New York City: McGraw-Hill Education.

O'hare, M. (1977). "Not On My Block You Don 't": Facilities sitting and the strategic importance of compensation. Cambridge, Massachusetts: Laboratory of Architecture and Planning, Massachusetts Institute of Technology.

Pondy, L. R. (1967). Organizational conflict: concepts and models. Administrative Science Quarterly, 12, 296-320.

Sun, J. (2013). The analysis of group event based on emotion sociology: the case study of molybdenum-copper alloy project in Shifang (Unpublished doctorial dissertation). East China University of Science and Technology, Shanghai.

Sun, L. (2005). Modernization and social transition. Beijing: Peking University Press.

Tan, S., \& Hu, X. (2013). The situation and strategy of social risk prevention of NIMBY projects in China. Emergency Management in China, 7, 54-58.

Wolsink, M. (1994). Entanglement of interests and motives: assumptions behind the NIMBY-theory on facility siting. Urban Studies, 31, 851866.

$\mathrm{Wu}$, M. (2010). Structural equation model: the practice and application of AMOS. Chongqing: Chongqing University Press. 
Zeng, P., \& Luo, G. (2006). A literature review on collective action mechanism. Open Times, 1, 111-123.

Zhao, D. (2005). A review of western social movement and revolution theory: from the perspective of China. Studi di Sociologia, 1, 168-209.

Zheng, W. (2011). The plight of NIMBY facilities planning: the case study of Shanghai maglev project. Urban Planning, 2, 74-81. 